\title{
Raising Charitable Children: The Effects of Verbal Socialization and Role-MOdeling on ChildREN's Giving
}

\author{
Mark Ottoni-Wilhelm \\ Department of Economics \\ Indiana University-Purdue University Indianapolis \\ Center on Philanthropy at Indiana University \\ Ye Zhang \\ Department of Economics \\ Indiana University-Purdue University Indianapolis \\ Center on Philanthropy at Indiana University \\ David B. Estell \\ Department of Counseling and Educational Psychology \\ Indiana University \\ Neil H. Perdue \\ School of Psychological Sciences \\ University of Indianapolis
}

Keywords: Socialization, Role-modeling, Cultural transmission, Charitable giving, Fixed effects JEL Classification: D10, J13, D64, Z13

This is the author's manuscript of the article published in final edited form as:

Ottoni-Wilhelm, M., Zhang, Y., Estell, D. B., \& Perdue, N. H. (2017). Raising charitable children: the effects of verbal socialization and rolemodeling on children's giving. Journal of Population Economics, 30(1), 189-224. https://doi.org/10.1007/s00148-016-0604-1 


\begin{abstract}
This paper uses nationally-representative data from the PSID and CDS to estimate the causal effects of two parent socialization actions on children's charitable giving. We develop a framework that shows how different identifying assumptions about parental response to timevarying unobserved child heterogeneity can be combined with the child fixed effects estimate and the difference over time between siblings estimate to infer a bound on the causal effect of a parental socialization action. Under the identifying assumption we think is most reasonable, our estimates imply that talking to children about giving raises the probability that children give by at least .13. We find no evidence that parental role-modeling affects children's giving, except among non-African-American girls. The results have implications for raising charitable children, and suggest that translational research is needed to learn how role-modeling, known to be effective in the laboratory, can be used effectively in the home.
\end{abstract}




\section{Introduction}

Little is known about the effects of actions parents take to socialize their children to give to charity. Although an extensive experimental literature from developmental psychology has established the existence of causal effects of role-modeling and verbal socialization on children's giving in laboratory settings (Eisenberg, Fabes, and Spinrad 2006), there is little empirical evidence about the existence and magnitude of causal effects from nationally-representative data collected from children's home settings. Lacking this evidence, it is not known whether parents are effectively using either rolemodeling or verbal socialization to raise charitable children.

In this paper we provide the first estimates of the causal effects of role-modeling and verbal socialization that use nationally-representative data from children in their home settings. Using data from the Panel Study of Income Dynamics' (PSID) 2001-2007 waves and its Child Development Supplement (CDS) 2002 and 2007, we estimate models of whether or not children give to charity, in which the main explanatory variables are the role-model of whether their parents give and whether their parents talk to them about giving. We estimate individual and sibling fixed effects specifications and two additional specifications seldom considered: across-time sibling fixed effects (older sibling data collected at an earlier time is differenced from younger sibling data collected at a later time) and a difference over time between siblings estimator. Estimates from these specifications identify causal effects depending upon the assumptions one makes about how parents' socialization actions respond to children's unobserved prosocial endowments. As is well-known, the sibling fixed effects estimator is consistent for the causal effect if parent socialization actions neither compensate nor reinforce differences between the child's specific endowment and his sibling's specific endowment (Behrman, Rosenzweig, and Taubman 1994; Rosenzweig and Wolpin 1995; Ermisch and Francesconi 2001). The individual fixed effects estimator is consistent regardless of parental response to the child-specific prosocial endowment, as long as the child's unobserved environment is time-constant.

However, it is hard to defend the assumption that the unobserved environment is time-constant in the child development context. If the parent's socialization actions respond to time-varying 
changes in the child's prosocial environment then the individual fixed effects estimator is no longer consistent. The difference over time between siblings estimator would be consistent as long as parental socialization neither compensates nor reinforces within-sibling differences that arise because of time-varying changes in the children's idiosyncratic environments. In this way, identifying assumptions about compensation/reinforcement reappear despite the use of child fixed effects. Maintaining that parents neither compensate nor reinforce within-sibling changes in environments is a strong identifying assumption.

In the paper we show how different identifying assumptions about compensation/reinforcement and substitution/complementarity, constructs from the intra-household allocation (Becker and Tomes 1976) and cultural transmission (Bisin and Verdier 2011) literatures, can be combined with the child fixed effects estimate and the difference over time between siblings estimate to infer a bound on the causal effect of parental action to socialize their children to give to charity. Which of the two estimates is interpreted as the bound depends upon qualitative assumptions about compensation/reinforcement and substitution/complementarity. Some combinations of identifying assumptions can be ruled out (e.g., reinforcement plus substitution) because they are incompatible with the estimates. Other assumptions (e.g., complementarity) may be given less weight because they counter much thinking in the intra-household allocation and cultural transmission literatures. In any event our results about the relationship between intra-household allocation and cultural transmission assumptions, the biases they imply, and our estimates narrow the range of causal interpretations about the effects of parental actions to socialize their children's giving. Our identification approach is generally applicable to empirical analyses using cross-time variation and cross-sibling variation to estimate the effects of a wide variety of parental investments to achieve child outcomes, and points to the kind of data needed to further narrow the range of causal interpretations in such analyses. 


\section{Background}

An extensive experimental literature in which adult experimenters role-model giving and/or talk about giving suggests that these are effective actions parents can take to socialize children's giving. ${ }^{1}$ Accordingly, role-modeling and talking to children about giving are emphasized in the practical literature on raising charitable children (Gallo and Gallo 2001; Weisman 2006). Despite this consensus, it is not known whether role-modeling and verbal socialization, effective in laboratory settings, are being effectively used in the home (Eisenberg and Mussen 1989, p. 156). Furthermore, because the experimental results are based on small, relatively homogeneous samples, generalization to the population has not been established. To our knowledge the only work at the population level are cross-sectional results that both parental role-modeling and verbal socialization have large associations with children's giving money to charities (Brown, Srivastava, and Taylor 2012; OttoniWilhelm, Estell, and Perdue 2011). These results provide initial evidence that causal effects seen in the laboratory may extend to home settings and generalize to the population, but it is not known how much of these cross-sectional associations are due to unobserved heterogeneity.

Standard approaches to mitigating unobserved heterogeneity include individual fixed effects and sibling fixed effects models. Most previous papers using sibling fixed effects are not explicitly investigating parental investment in children, and therefore do not use a conceptual framework based on intra-household allocation (e.g., Altonji and Dunn 1996a, 1996b; Geronimus and Korenman 1992). However, a standard conceptual framework in the parental investment literature is Becker and Tomes' (1976) intra-household allocation model. The Becker-Tomes model posits that a parent's investment in her children responds to differences in child-specific endowments either

\footnotetext{
${ }^{1}$ For examples of role-modeling experiments, see Bryan and Walbek (1970), Dressel and Midlarsky (1978), Grusec, Sass-Kortsaak, and Simutis (1978), Israel and Raskin (1979), Owens and Ascione (1991), Rice and Grusec (1975), Rushton (1975), White and Burnam (1975); cf. Lipscomb, Bregman, and McAllister (1983). For experiments that involve talking about donating, see Dlugokinski and Firestone (1974), Dressel and Midlarsky (1978), EisenbergBerg and Geisheker (1979), Grusec, Sass-Kortsaak, and Simutis (1978), Israel and Brown (1979), Israel and Raskin (1979), McGrath, Wilson, and Frasetto (1995), Perry, Bussey, and Freiberg (1981), Rice and Grusec (1975), Smith, Leinbach, Stewart, and Blackwell (1983); cf. Bryan and Walbek (1970), Lipscomb, Bregman, and McAllister (1983). This list is not exhaustive, see Eisenberg, Fabes, and Spinrad (2006) and the earlier Eisenberg and Fabes (1998) for authoritative reviews. Results from the role-modeling experiments are robust across most of the experiments, while results from the talking-about-donating experiments are somewhat more mixed.
} 
by compensating for those differences (investing more in the less endowed child) or by reinforcing the differences (investing more in the more endowed child). Under the identifying assumption that parental investment is neutral-neither compensating nor reinforcing differences between children's specific endowments-sibling fixed effects specifications consistently estimate causal effects of parental investment. Because neutrality is a strong assumption, the utility of sibling fixed effects models in this situation can be questioned (Behrman, Rosenzweig, and Taubman 1994; Rosenzweig and Wolpin 1995; also see Ermisch and Francesconi 2001, pp. 263ff). Individual fixed effects would seem preferable because they yield consistent estimates of causal effects regardless of whether parents compensate or reinforce child-specific endowments, under the identifying assumption that other unobserved heterogeneities that are correlated with parental investments, such as the child-specific environment, is time-constant.

A problem with individual fixed effects applied to children during the childhood years is that the child development literature calls into question the assumption that child-specific environments are time-constant. As the child ages, the child-specific environment changes through encounters with formal institutions (child-care, schools, neighborhood organizations, religious congregations, media) and informal networks (friends, neighbors), and parents would likely respond to these changes (Berk 2003; Bisin and Verdier 2011). In our application changes in the child-specific environment can lead to changes in the child's unobserved prosocial values that in turn affect giving. The term "environment" is more familiar to economists, and we will use this term synonymously with "prosocial values." It is well-known that prosocial values change as children age (Eisenberg 1986).

Becker and Tomes (1979, p. 1167) use now standard "family income" reasoning to argue that parents invest less in children when child-specific environments ("endowment luck" in their terminology) increase. This kind of parental substitution in response to changes in environments is akin to "cultural substitution" from the cultural transmission literature (Bisin and Verdier 2011). Mapping these constructs to our charitable giving application, "parental investment" is action taken to socialize children to give ("vertical transmission") and changes in child-specific prosocial 
values come about through encounters with formal institutions and informal networks that also socialize giving ("horizontal transmission"). Bisin and Verdier (2001) show that if parental socialization and horizontal socialization are substitutes then the outcome being socialized will become heterogeneous in the population; alternatively if parental and horizontal socialization are strong enough cultural complements the outcome being socialized will become homogeneous. The fact that charitable giving is heterogeneous in the population suggests that parental and horizontal socializations are cultural substitutes, or at least any cultural complementarity is not strong. ${ }^{2}$ If parental actions to socialize children's giving and horizontal socialization are cultural substitutes then child fixed effects estimator of the effect of parental actions would be downward biased.

A potential approach to mitigating the bias created by time-varying child-specific prosocial values is to model the unobservable with a child-specific trend. This approach requires at least three observations per child across time, a requirement not satisfied by the data available for many studies, including ours. Alternatively, the availability of sibling data permits the modeling of a family-specific trend: the "difference over time between siblings" estimator (Levine, Gustafson, and Velenchik 1997). While this estimator differences out unobserved time-varying environment that is common to both siblings, it also re-introduces in a time-varying context the compensation/reinforcement constructs from the intra-household allocation model. Hence both the intra-household allocation and cultural transmission models are necessary to understand the differences in potential biases between the child fixed effects and the difference over time between siblings estimators. Previous work has not derived the differences in potential biases.

The present paper derives the differences in biases under different qualitative identifying assumptions about compensation/reinforcement and cultural substitution/complementarity. Our empirical work shows that knowledge of these differences combined with the child fixed effects and difference over time between siblings estimates can be used to infer a bound on the causal effect of a parental socialization action. This is similar in spirit to the approach developed by Ribar (1999) in which a qualitative identifying assumption about the relationship between the child-

\footnotetext{
${ }^{2}$ Based on our calculations using the PSID, in calendar years 2000, 2002, 2004, 2006, and 2008 the percent of the American population who give was always in the range 65 to 69 .
} 
specific covariance (between the unobserved child-specific endowments in the outcome equation and the "action" equation) and cross-sibling covariance combined with the sibling fixed effects and sibling IV estimates suggest bounds on causal effects. Our innovations relative to Ribar's work are deriving the identifying assumptions in terms of the intra-household allocation and cultural transmission models, a framework that is well suited to study the effects of parental investments on children's outcomes, and modeling time-varying heterogeneity.

\section{Econometric Framework and Identification Problem}

We investigate the effect of parental socialization actions on children's charitable giving using a model similar to that in Behrman et al. (1994), Rosenzweig and Wolpin (1995), and Ermisch and Francesconi (2001). Using this framework we analyze the identification problem that arises in the presence of time-varying heterogeneity. Consider a model of charitable giving $Y_{i j t}$ for child $i$ in family $j$ at time $t$ :

$$
Y_{i j t}=\beta X_{i j t}+\mu_{j}+\alpha_{i j}+\theta_{i j t}+v_{i j t}
$$

where $X_{i j t}$ is the parent's socialization action. There are four variables in (1) that model different components of a child's unobserved heterogeneity that affects a child's giving: $\mu_{j}$ is a familyspecific time-constant prosocial endowment that is common to all members of the family $j$ (e.g., due to genetic similarity); $\alpha_{i j}$ is a child-specific prosocial endowment; $\theta_{i j t}$ models time-varying idiosyncratic prosocial values; and $v_{i j t}$ models random shocks to the child's giving. The difference between $\theta_{i j t}$ and $v_{i j t}$ is that in our model, parental socialization action will respond to $\theta_{i j t}$ but not to $v_{i j t}$. The object of estimation is parameter $\beta$, the effect of socialization action on children's

giving. In our empirical work we consider two socialization actions: talking about giving and role-modeling, but in this section, to ease discussion we develop the model in terms of one action, e.g. talking about giving. For a two-child family, sibling $k$ 's outcome equation parallels (1):

$$
Y_{k j t}=\beta X_{k j t}+\mu_{j}+\alpha_{k j}+\theta_{k j t}+v_{k j t}
$$


Because the parental socialization decisions are made within a family context, the socialization variables $X_{i j t}$ and $X_{k j t}$ are themselves functions of family-related and child-related unobservables:

$$
X_{i j t}=\gamma_{1} \alpha_{i j}+\gamma_{2} \alpha_{k j}+\delta \mu_{j}+\pi_{1} \theta_{i j t}+\pi_{2} \theta_{k j t}+u_{i j t}
$$

and

$$
X_{k j t}=\gamma_{1} \alpha_{k j}+\gamma_{2} \alpha_{i j}+\delta \mu_{j}+\pi_{1} \theta_{k j t}+\pi_{2} \theta_{i j t}+u_{k j t}
$$

where $u_{i j t}$ and $u_{k j t}$ model random socialization shocks unrelated to children's endowments and idiosyncratic prosocial values. The parameters $\gamma_{1}, \gamma_{2}, \delta, \pi_{1}$, and $\pi_{2}$, model the idea that there is unobserved heterogeneity across families and across children common to both children's giving behavior and parent's socialization decisions. As is well-known, unless all these parameters are zero, estimating (1) across children with heterogeneous $\mu_{j}, \alpha_{i j}$, and $\theta_{i j t}$ is inconsistent for the causal effect $\beta$.

In equations (3) and (4), $\delta$ is the effect of the family-specific prosocial endowment on parent's socialization of both children. Two parameters model the parent's socialization responses to the child's own specific prosocial endowment $\left(\gamma_{1}\right)$ and his sibling's specific prosocial endowment $\left(\gamma_{2}\right)$. Similarly $\pi_{1}$ and $\pi_{2}$ model socialization responses to the own and sibling idiosyncratic time-varying prosocial values. Own and sibling endowments and prosocial values are drawn from the same distribution so that $\operatorname{var}\left(\alpha_{i j}\right)=\operatorname{var}\left(\alpha_{k j}\right)$ and $\operatorname{var}\left(\theta_{i j t}\right)=\operatorname{var}\left(\theta_{k j t}\right)$. Likewise, own and sibling random shocks to giving are drawn from the same distribution so that $\operatorname{var}\left(v_{i j t}\right)=\operatorname{var}\left(v_{k j t}\right)$, as are the random socialization shocks $\operatorname{var}\left(u_{i j t}\right)=\operatorname{var}\left(u_{k j t}\right)$.

To see the identification problems associated with different model specifications, we derive the expressions for the observed variances of children's charitable giving and parent's socialization actions and their covariances within child over time and across siblings in terms of the parameters of the model. After substituting equations (3) and (4) into (1) and (2) to obtain the reduced form 
for $Y$, the within-child across-time expressions are:

$$
\Delta^{T} Y_{i j}=\left(1+\beta \pi_{1}\right)\left(\theta_{i j t}-\theta_{i j t-1}\right)+\beta \pi_{2}\left(\theta_{k j t}-\theta_{k j t-1}\right)+\beta\left(u_{i j t}-u_{i j t-1}\right)+\left(v_{i j t}-v_{i j t-1}\right)
$$

and

$$
\Delta^{T} X_{i j}=\pi_{1}\left(\theta_{i j t}-\theta_{i j t-1}\right)+\pi_{2}\left(\theta_{k j t}-\theta_{k j t-1}\right)+\left(u_{i j t}-u_{i j t-1}\right) .
$$

where $\Delta^{T}$ indicates that the difference is taken in the time dimension.

Based on expressions (5) and (6), the within-child variance and covariance are:

$$
\operatorname{var}\left(\Delta^{T} X_{i j}\right)=2\left(\pi_{1}^{2}+\pi_{2}^{2}\right) \sigma_{\theta}^{2}+2 \sigma_{u}^{2}
$$

and

$$
\operatorname{cov}\left(\Delta^{T} Y_{i j}, \Delta^{T} X_{i j}\right)=2\left(\pi_{1}+\beta \pi_{1}^{2}+\beta \pi_{2}^{2}\right) \sigma_{\theta}^{2}+2 \beta \sigma_{u}^{2}
$$

The child fixed effects estimator $b^{T}$ is (8) divided by (7) and its probability limit is:

$$
\operatorname{plim} b^{T}=\beta+\frac{\pi_{1} \sigma_{\theta}^{2}}{\left(\pi_{1}^{2}+\pi_{2}^{2}\right) \sigma_{\theta}^{2}+\sigma_{u}^{2}} .
$$

$b^{T}$ is consistent if $\sigma_{\theta}^{2}=0$ or $\pi_{1}=0$ : the child-specific prosocial values do not vary over time, or if they do, the parental socialization action does not respond to them.

The within-sibling difference expressions are:

$$
\Delta^{J} Y_{i t}=\left(1+\beta \gamma_{1}-\beta \gamma_{2}\right)\left(\alpha_{i j}-\alpha_{k j}\right)+\left(1+\beta \pi_{1}-\beta \pi_{2}\right)\left(\theta_{i j t}-\theta_{k j t}\right)+\beta\left(u_{i j t}-u_{k j t}\right)+\left(v_{i j t}-v_{k j t}\right)
$$

and

$$
\Delta^{J} X_{i t}=\left(\gamma_{1}-\gamma_{2}\right)\left(\alpha_{i j}-\alpha_{k j}\right)+\left(\pi_{1}-\pi_{2}\right)\left(\theta_{i j t}-\theta_{k j t}\right)+\left(u_{i j t}-u_{k j t}\right) .
$$

where $\Delta^{J}$ indicates that the difference is taken within sibling pairs at time $t$. The corresponding 
variance and covariance terms are:

$$
\operatorname{var}\left(\Delta^{J} X_{i t}\right)=2\left(\gamma_{1}-\gamma_{2}\right)^{2} \sigma_{\alpha}^{2}+2\left(\pi_{1}-\pi_{2}\right)^{2} \sigma_{\theta}^{2}+2 \sigma_{u}^{2}
$$

and

$$
\operatorname{cov}\left(\Delta^{J} Y_{i t}, \Delta^{J} X_{i t}\right)=2\left(1+\beta \gamma_{1}-\beta \gamma_{2}\right)\left(\gamma_{1}-\gamma_{2}\right) \sigma_{\alpha}^{2}+2\left(1+\beta \pi_{1}-\beta \pi_{2}\right)\left(\pi_{1}-\pi_{2}\right) \sigma_{\theta}^{2}+2 \beta \sigma_{u}^{2}
$$

The sibling fixed effects estimator $b^{J}$ is (13) divided by (12), and its probability limit is:

$$
\operatorname{plim} b^{J}=\beta+\frac{\left(\gamma_{1}-\gamma_{2}\right) \sigma_{\alpha}^{2}+\left(\pi_{1}-\pi_{2}\right) \sigma_{\theta}^{2}}{\left(\gamma_{1}-\gamma_{2}\right)^{2} \sigma_{\alpha}^{2}+\left(\pi_{1}-\pi_{2}\right)^{2} \sigma_{\theta}^{2}+\sigma_{u}^{2}} .
$$

Assuming $\sigma_{\alpha}^{2}$ and $\sigma_{\theta}^{2}$ are not zero, $b^{J}$ is consistent if $\gamma_{1}-\gamma_{2}=0$ and $\pi_{1}-\pi_{2}=0$. We will interpret these identifying assumptions below.

If we take the difference over time between siblings, it can be shown that the estimator $b^{J T}$ has:

$$
\operatorname{plim} b^{J T}=\beta+\frac{\left(\pi_{1}-\pi_{2}\right) \sigma_{\theta}^{2}}{\left(\pi_{1}-\pi_{2}\right)^{2} \sigma_{\theta}^{2}+\sigma_{u}^{2}} .
$$

Finally, we can construct a within-sibling estimator for $\beta$ by taking the difference between the older sibling measured at an earlier time and the younger sibling measured at a later time. The resulting estimator $b^{J D T}$ can be shown to have:

$$
\operatorname{plim} b^{J D T}=\beta+\frac{\left(\gamma_{1}-\gamma_{2}\right) \sigma_{\alpha}^{2}+\pi_{1} \sigma_{\theta}^{2}}{\left(\gamma_{1}-\gamma_{2}\right)^{2} \sigma_{\alpha}^{2}+\left(\pi_{1}^{2}+\pi_{2}^{2}\right) \sigma_{\theta}^{2}+\sigma_{u}^{2}}
$$

We turn now to the interpretation of the biases in (9) and (15) using constructs from the intrahousehold allocation (Becker and Tomes 1976) and cultural transmission (Bisin and Verdier 2011) models. We focus on the $b^{T}$ and $b^{J T}$ estimators because our empirical results indicate that $\gamma_{1-\gamma} \gamma_{2}=$ 0 , and conditional on $\gamma_{1}-\gamma_{2}=0: \operatorname{plim} b^{J D T}=\operatorname{plim} b^{T}$ and $\operatorname{plim} b^{J}=\operatorname{plim} b^{J T}$. Conditioning on $\gamma_{1}-\gamma_{2}=0$ also allows us to focus on the innovation in our analysis: the idiosyncratic time- 
varying prosocial values and the associated response parameters $\pi_{1}$ and $\pi_{2}$. Figure 1 summarizes how each $\left(\pi_{1}, \pi_{2}\right)$ pair maps to qualitative assumptions about parental (a) compensation-versusreinforcement in response to changes in the difference between children's prosocial values and (b) substitution-versus-complementarity in response to changes in the sum of children's prosocial values, and maps these assumptions to the directions and relative magnitudes of the biases in the $b^{T}$ and $b^{J T}$ estimators.

The $\pi_{2}=\pi_{1}$ line partitions the $\pi_{1}, \pi_{2}$ plane such that to the northwest are $\left(\pi_{1}, \pi_{2}\right)$ pairs corresponding to parental compensation and to the southeast are pairs corresponding to reinforcement. For example, if $\pi_{1}>0, \pi_{2}>0$, and $\pi_{2}>\pi_{1}$, in response to a one-unit exogenous increase in child $i$ 's prosocial values the parent would increase talking to child $i$ by $\pi_{1}$ but also would increase talking to child $k$ by $\pi_{2}$ so that $\Delta^{T}\left(X_{i j t}-X_{k j t}\right)=\pi_{1}-\pi_{2}<0$ : the parent talks relatively more to child $k$ who did not experience the increase in prosocial values, hence compensating child $k$. Conversely, if $\pi_{1}>0, \pi_{2}<0$ then $\Delta^{T}\left(X_{i j t}-X_{k j t}\right)=\pi_{1}-\pi_{2}>0$ : the parent talks relatively more to child $i$ thereby reinforcing the exogenous change in prosocial values that favored child $i$. If $\pi_{2}=\pi_{1}$ the parent is unresponsive ("neural") to within-sibling heterogeneity in $\theta . \pi_{2}=\pi_{1}$ implies equation (3) can be re-written as:

$$
X_{i j t}=\gamma_{1}\left(\alpha_{i j}+\alpha_{k j}\right)+\delta \mu_{j}+\pi_{1}\left(\theta_{i j t}+\theta_{k j t}\right)+u_{i j t}
$$

where we recall that the discussion is conditional on $\gamma_{1}-\gamma_{2}=0$.

Equation (3') makes plain an interesting interpretation of the identifying assumptions behind sibling fixed effects models: the assumptions permit a parental response to the sum total of her children's endowments, and to the sum total of prosocial values, but not to the within-sibling differences. It is as if in making her socialization responses to endowments and prosocial values, the parent uses her "average child" (meaning the average endowment and the average prosocial values) to determine her socialization responses to both children. Consistency of the difference over time between siblings estimator $b^{J T}$ does not require this identifying assumption in terms of endowments $\left(\gamma_{1}=\gamma_{2}\right.$ is not necessary), but does require it in terms of prosocial values $\left(\pi_{2}=\pi_{1}\right.$ is 
necessary).

In a similar manner the $\pi_{2}=-\pi_{1}$ line partitions the $\pi_{1}, \pi_{2}$ plane such that to the southwest are $\left(\pi_{1}, \pi_{2}\right)$ pairs corresponding to cultural substitution and to the northeast complementarity. Recall that in the $\pi_{1}>0, \pi_{2}>0$, and $\pi_{2}>\pi_{1}$ example above (northeast of the $\pi_{2}=-\pi_{1}$ line), although the parent responded by talking relatively more to child $k$, the parent talked more to both children. Hence the parent complemented the exogenous increase in the sum total of her children's prosocial values by increasing the sum total of her talking about giving to children: $\Delta^{T}\left(X_{i j t}+X_{k j t}\right)=\pi_{1}+\pi_{2}>0$. If instead $\pi_{1}<0, \pi_{2}>0$, and $\pi_{2}<-\pi_{1}$, then $\Delta^{T}\left(X_{i j t}+X_{k j t}\right)=$ $\pi_{1}+\pi_{2}<0$, the parent reduces the sum total amount of talking to her children, hence substituting away from talking about giving.

In the last example note that while substituting in terms of the sum total amount of talking, the parent talks less to child $i$ and more to child $k$, thereby compensating the difference while substituting the sum total. The $\pi_{2}=\pi_{1}$ and $\pi_{2}=-\pi_{1}$ lines partition the $\pi_{1}, \pi_{2}$ plane into four triangles in which the $\left(\pi_{1}, \pi_{2}\right)$ pairs correspond to compensation of differences and substitution of the sum total (the west triangle), reinforcement and substitution (the south triangle), reinforcement and complementarity (the east triangle), and compensation and complementarity (the north triangle). Consider $\left(\pi_{1}, \pi_{2}\right)$ pairs such that $\pi_{1}^{2}+\pi_{2}^{2}=S$ where $S$ is fixed. $\left(\pi_{1}, \pi_{2}\right)$ pairs on a circle with a larger radius $\sqrt{S}$ correspond to a stronger overall parental response to changes in children's prosocial values. Moving around a circle of radius $\sqrt{S}$, we hold the overall strength of response constant while moving to $\left(\pi_{1}, \pi_{2}\right)$ pairs with different relative strength of compensation-versusreinforcement and different relative strength of substitution-versus-complementarity.

In quadrant $4\left(\pi_{1}<0\right.$ and $\left.\pi_{2}>0\right)$, compensation is relatively strong compared to the compensatory $\left(\pi_{1}, \pi_{2}\right)$ pairs on the same $\sqrt{S}$-circle but in quadrant $1\left(\pi_{1}>0, \pi_{2}>0\right.$, and $\left.\pi_{2}>\pi_{1}\right)$ or quadrant $3\left(\pi_{1}<0, \pi_{2}<0\right.$, and $\left.\pi_{2}>\pi_{1}\right)$. At $\pi_{2}=-\pi_{1}$ in quadrant 4 compensation is the strongest: in response to a one-unit increase in the prosocial values of child $i$ the parent would decrease talking to child $i$ by the same amount she increases talking to child $k$, so that the difference $\Delta^{T}\left(X_{i j t}-X_{k j t}\right)=\pi_{1}-\pi_{2}=2 \pi_{1}<0$ obtains its minimum, relative to all other $\left(\pi_{1}, \pi_{2}\right)$ pairs 
on the same $\sqrt{S}$-circle. Conversely, at $\pi_{2}=-\pi_{1}$ in quadrant 2 , reinforcement is the strongest. In quadrant 3 cultural substitution is relatively strong: both $\pi_{1}$ and $\pi_{2}$ are negative, implying that the parent responds to exogenous increases in her children's prosocial values by taking less about giving to both children. At $\pi_{2}=\pi_{1}$ in quadrant 3, substitution is the strongest. At $\pi_{2}=\pi_{1}$ in quadrant 1, complementarity is the strongest.

The $\pi_{1}, \pi_{2}$ plane also can be partitioned into regions characterized by different directions of bias in $b^{T}$ and $b^{J T}$, following from straightforward inspection of equations (9) and (15). For $\left(\pi_{1}, \pi_{2}\right)$ pairs in the region northwest of the $\pi_{2}=\pi_{1}$ line, but to the right of the $\pi_{2}$ axis, $b^{T}$ is positively biased and $b^{J T}$ negatively biased. Moving to the left of the $\pi_{2}$ axis but staying to the north of the $\pi_{2}=\pi_{1}$ line (in quadrant 3 ) is the region in which both $b^{T}$ and $b^{J T}$ are negatively biased. South of the $\pi_{2}=\pi_{1}$ line in quadrant 3 and to the left of the $\pi_{2}$ axis is the region in which $b^{T}$ is negatively biased and $b^{T J}$ positively biased. In the remaining region comprising all of quadrant 2 and half of quadrant 1 both $b^{T}$ and $b^{T J}$ are positively biased.

Finally, the $\pi_{1}, \pi_{2}$ plane can be partitioned into regions in which the magnitude of the bias in either $b^{T}$ or $b^{J T}$ is smaller. To see this, compare the bias magnitudes from equations (9) and (15). If both bias terms are positive $\left(\pi_{1}>0, \pi_{1}-\pi_{2}>0\right)$ or both negative $\left(\pi_{1}<0, \pi_{1}-\pi_{2}<0\right)$ then:

$$
\left|\operatorname{bias}\left(b^{T}\right)\right|-\left|\operatorname{bias}\left(b^{J T}\right)\right|\left\{\begin{array}{l}
<0 \\
=0 \\
<0
\end{array} \quad \text { iff } \quad\left[R-\left(\pi_{1}^{2}-\pi_{2}^{2}\right)\right] \times \pi_{2}\left\{\begin{array}{l}
<0 \\
=0
\end{array}\right.\right.
$$

where $R \equiv \frac{\sigma_{u}^{2}}{\sigma_{\theta}^{2}}$. The equality in the right-hand part of $(17)$ defines the $\left(\pi_{1}, \pi_{2}\right)$ pairs at which the bias magnitudes are the same, the equal bias boundaries. In this case the boundaries can be expressed parsimoniously: $\pi_{2}=0$ and $\pi_{1}^{2}-\pi_{2}^{2}=R$, a hyperbola. If the bias terms have different signs then the equal bias boundary is the solution to:

$$
\pi_{2}^{3}-\left(2 \pi_{1}\right) \pi_{2}^{2}+\left(3 \pi_{1}^{2}+R\right) \pi_{2}-2 \pi_{1}\left(\pi_{1}^{2}+R\right)=0
$$


In this case the equal bias boundary is the real root of the cubic equation (18) in which the parameters are functions of $\pi_{1}$. There is only one real root (the discriminant is positive), but the solution of $\pi_{2}$ in terms of $\pi_{1}$ is not parsimonious. ${ }^{3}$ We have graphed the equal bias boundaries in Figure 1. The regions of the $\pi_{1}, \pi_{2}$ plane in which the magnitude of the bias in $b^{T}\left(b^{J T}\right)$ is smaller are denoted "T" ("JT").

Note that the circle $\pi_{1}^{2}+\pi_{2}^{2}=R$ benchmarks the overall strength of parental response. For $\left(\pi_{1}, \pi_{2}\right)$ pairs such that $\pi_{1}^{2}+\pi_{2}^{2}=R$, the time-varying portion of the parental variation in verbal socialization is equally split between the component describing variation in response to changes in children's prosocial values and the component describing idiosyncratic variation: $\left(\pi_{1}^{2}+\pi_{2}^{2}\right) \sigma_{\theta}^{2}=\sigma_{u}^{2}$. $\left(\pi_{1}, \pi_{2}\right)$ pairs such that $\pi_{1}^{2}+\pi_{2}^{2}>R$ imply that variation in response to changes in children's prosocial values accounts for more than half of the total variation in the time-varying components. Pairs such that $\pi_{1}^{2}+\pi_{2}^{2}<R$ imply relatively weaker overall strength of parental response, so that response to changes in children's prosocial values accounts for less than half of the total variation.

We will use Figure 1 to organize our discussion of the estimates. Qualitative assumptions about (a) compensation-versus-reinforcement, (b) substitution-versus-complementarity, and (c) the overall strength of parental response serve as identifying assumptions that, along with the estimation results, lead to bounds for the causal effect of verbal socialization on children's giving. Of course, a set of quantitative assumptions - precise values for $\pi_{1}$ and $\pi_{2}$-could be used to develop an estimator that would be consistent for $\beta$, as long as the precise $\pi_{1}$ and $\pi_{2}$ values actually matched the data generating process. This is what individual fixed effects and sibling fixed effects estimators do. The difference over time between siblings estimator imposes a quantitative identifying assumption that $\pi_{2}=\pi_{1}$, and if that matches the data generating process then $b^{J T}$

\footnotetext{
${ }^{3}$ It can be shown that:

$$
\begin{aligned}
\pi_{2} & =\left[\frac{1}{9}\left(\frac{8 \pi_{1}^{3}+18 \pi_{1} R}{3}+\sqrt{21 \pi_{1}^{6}+57 \pi_{1}^{4} R+51 \pi_{1}^{2} R^{2}+3 R^{3}}\right)\right]^{1 / 3} \\
& +\left[\frac{1}{9}\left(\frac{8 \pi_{1}^{3}+18 \pi_{1} R}{3}-\sqrt{21 \pi_{1}^{6}+57 \pi_{1}^{4} R+51 \pi_{1}^{2} R^{2}+3 R^{3}}\right)\right]^{1 / 3} \\
& +\frac{2}{3} \pi_{1} .
\end{aligned}
$$
}


is consistent for $\beta$. Figure 1 helps visualize how strong the $\pi_{2}=\pi_{1}$ identifying assumption is in terms of the intra-household allocation and cultural transmission literatures: the assumption implies that parents neither compensate nor reinforce exogenous changes in the difference between their children's prosocial values, and treat exogenous changes in the sum total of their children's values as either the strongest possible complements or the strongest possible substitutes in relative terms holding $\pi_{1}^{2}+\pi_{2}^{2}$ constant at $\pi_{1}^{2}+\pi_{2}^{2}=S$. The individual fixed effects estimator imposes a different quantitative identifying assumption: $\pi_{1}=0$. From Figure 1 we see that $\pi_{1}=0$ implies moderately strong compensation combined with moderately strong complementarity (the positive $\pi_{2}$ axis), or moderately strong reinforcement and moderately strong substitution (the negative $\pi_{2}$ axis). Again, "strength" is to be understood in relative terms. ${ }^{4}$

Many economists familiar with the intra-household allocation and cultural transmission literatures would be uncomfortable with tightly holding to the quantitative identifying assumptions underlying either the difference over time between siblings or individual fixed effects estimators. In the Discussion section we develop arguments favoring identifying assumptions in which parents compensate differences between their children's prosocial values and treat exogenous changes in the sum total of their children's values as substitutes, that is, the west triangle in Figure 1. Whether the reader agrees with these arguments or not, we can use Figure 1 as a tool to help understand how the $b^{T}$ and $b^{J T}$ estimation results in combination with qualitative identification assumptions rooted in constructs from the intra-household allocation and cultural transmission literatures lead to bounds on the causal effect of verbal socialization.

\footnotetext{
${ }^{4}$ To be clear, by "relative" we mean relative to other $\left(\pi_{1}, \pi_{2}\right)$ pairs on the same $\sqrt{S}$-circle. Pairs $\left(0, \pi_{2}\right)$ have moderately strong compensation/complementarity (if $\pi_{2}>0$ ) or moderately strong reinforcement/substitution (if $\left.\pi_{2}<0\right)$ relative to other $\left(\pi_{1}, \pi_{2}\right)$ pairs on the same $\sqrt{S}$-circle. By "moderately strong" we mean that (a) the $\left(0, \pi_{2}\right)$ pairs on the $\sqrt{S}$-circle are midway between zero compensation (on the $\pi_{2}=\pi_{1}$ line) and the strongest compensation (on the $\pi_{2}=-\pi_{1}$ line) combined with (b) being midway between zero complementarity (on the $\pi_{2}=-\pi_{1}$ line) and the strongest complementarity (on the $\pi_{2}=\pi_{1}$ line), or (c) midway between zero reinforcement and the strongest reinforcement combined with (d) zero substitution and the strongest substitution. If $S$ is small then compensation/complementarity (or reinforcement/substitution) are small in terms of the parent's absolute overall response.
} 


\section{Data}

We estimate different model specifications of children's giving using data from the Panel Study of Income Dynamics (PSID) and its Child Development Supplement (CDS). The first wave of the CDS was fielded in 1997 and drew its sample children from PSID-responding family units. From each family unit up to two children aged 0-12 were selected, and interviews were completed for 3,563 children. The CDS-2 sample consists of 2,907 of these children who were in PSID-responding family units in 2001, and the CDS-3 sample consists of 1,506 children in responding family units in 2005. CDS-2 interviews occurred fall 2002 to spring 2003 when the children were ages 5-19, and CDS-3 interviews occurred fall 2007 to spring 2008 when the children were ages 10-19. The CDS sample has gotten smaller over time as the 1997 age 0-12 cohort ages out to become sample for the PSID's Transition into Adulthood (TA) survey or the PSID core family interview.

In CDS-2 and CDS-3 children ages 8 and older were asked the question "Did you give some of your money last year-if only a few pennies-to a church, synagogue, or another charity that helps people who are not part of your family?" Answers to this question form our dependent variable. The child's primary care giver, usually the child's mother, was asked a parallel question "Do you ever talk to (CHILD) about giving some of (his/her) money-if only a few pennies-to a church, synagogue, or another charity?" Answers to this question form our verbal socialization indicator.

Data on giving to religious congregations and charitable organizations from the PSID's 20012007 core family interviews form our role-modeling variables. To match the child giving and verbal socialization variables, our main role-modeling variable is an indicator of whether the parent gave to a religious congregation in which the primary purpose is worship and spiritual development or a "secular" charity whose primary purpose is to help people in need, provide health care, provide education, youth and family services, improve neighborhoods, provide international aid, etc. Our main role-modeling variable uses this indicator from the 2001 and 2007 waves. For sensitivity analyses we construct alternative mappings of the core interview giving data to role-modeling variables: (a) separate indicators for religious giving and secular giving, and (b) amounts given (in

logs). We also use the 2003 and 2005 waves, along with 2001 and 2007, to attempt to capture what 
might be long-term changes in role-modeling. We will describe this "long-term change" measure when we present the sensitivity analysis.

We work with three analysis samples. Table 1 presents their weighted descriptive statistics. The first sample, the child fixed effects sample, consists of 936 children who were old enough in CDS-2 to have been asked the giving question, and young enough in CDS-3 to have not aged out. The descriptive statistics pool the observations from both time periods. The average age of the children is 13.2 years, aging from 10.7 in CDS-2 to 15.7 in CDS-3. Forty-seven percent are girls, and 17 percent African-American. The percentage of children who give is 71.4, 71.8 percent of parents talk to their child about giving, and 68.4 percent role-model giving.

The remaining rows describe the other independent variables: family structure, residential moves, family income, and the child's income (from allowances and jobs) and savings. The warmth variable is the parent's report of seven items on a 0-4 scale about how often in the past month she told the child she loved him/her, told the child she appreciated something he/she did, spent time with the child doing one of his/her favorite activities, talked with the child about matters important to him/her, etc. (warmth $=0$ is "not in the past month" and warmth $=4$ is "every day"). The 2.666 indicates that on average the parent provides these indicators of warmth between once a week (warmth $=2$ ) and several times a week (warmth $=3$ ). We include parental warmth because of the prominent role it plays in developmental psychology theory about prosocial behavior (e.g., Eisenberg et al. 2006, p. 666). The reading score is the combined WJ-R Letter-Word and Passage Comprehension Tests, and the math score is the child's achievement on the WoodcockJohnson Revised (WJ-R) Applied Problems Test. Both scores are age-standardized. We include measures of the child's cognitive ability as proxies for the ability to engage in more abstract moral reasoning, which in turn is associated with charitable giving (Wilhelm and Bekkers 2010).

Column 2 describes the sibling fixed effects sample. The sample consists of 576 sibling pairs (1,152 children) in which both children were old enough in CDS-2 to have been asked the giving question. A sibling pair is defined to be two children who share at least one parent in common. Most of the sibling pairs share both parents (78 percent) or otherwise have a common birth mother 
(another 20 percent). Column 3 describes the across-time sibling fixed effects sample consisting of an older sibling in CDS-2 and a younger sibling in CDS-3. Finally, among the 576 sibling-pairs in column 2 there are 144 in which both siblings are present in CDS-2 and CDS-3. We use this sample in our difference over time between siblings model. We also estimated sibling fixed effects models for the 337 sibling pairs in CDS-3, but we do not present the results because they are qualitatively similar to results from the CDS-2 sibling sample.

Table 2 describes the amount of within-variation in the three analysis samples: Panel A for the child fixed effects sample, Panel B for the sibling fixed effects sample, and Panel C for the across-time sibling fixed effects sample. The statistics are not weighted. Panel A contains the 903 children to be used in the child fixed effects model (the few children with missing data in one of the two years are excluded). There is a lot of within-child across-time variation in children's giving, parent's talking, and role-modeling: 39, 35, and 29 percent of the total variation is within-child. This is more than the across-time variation in log family income (21 percent). Panel A also shows that 13.4 percent of children switch off giving, while 17.7 switch on. Hence, 31 percent of children switch from giving to not giving or vice versa. Twenty-eight percent of parents switch from talking to not talking or vice versa, and 26.8 percent switch role-modeling.

Panel B shows an amount of within-sibling variation in giving (38 percent) similar to Panel A's within-child variation. However, there is much less within-sibling variation in parent's talking about giving. Only 12.9 percent of parents talked to one sibling but not the other about giving. This suggests that there will be lower precision in the estimates of the sibling fixed effects model. Panel C shows much more within-sibling variation in parent's talking about giving, because the talking is occurring at different times in this sibling sample: 27.8 percent of parents talked to one sibling but not the other about giving. The within-sibling variation in Panel $\mathrm{C}$ is similar to the within-child variation in Panel A. 


\section{Empirical Results}

Table 3 presents estimates of a linear probability model of children's giving using the child fixed effects sample. The estimates in this and subsequent tables are unweighted. ${ }^{5}$ Columns 1 and 2 are OLS estimates pooling the data from the two time periods. The specification in column 1 contains only the parental socialization actions. Both actions are associated with the children's giving: talking about giving is associated with a 13.5 percentage point increase in the probability of giving and role-modeling with a 6.2 point increase. Both associations are precisely estimated. Column 2 adds controls for demographics, resources, parental warmth, and children's cognitive ability. The talking about giving and role-modeling associations are little changed. Among the controls, girls, African-American children, and those with higher math ability are more likely to give. Children in female-headed households are less likely to give. Columns 3 and 4 present the child fixed effects estimates. The estimated effect of talking about giving is roughly 13 percentage points on children's probability of giving. In contrast the estimated effect of role-modeling is essentially zero.

Table 4 presents the sibling fixed effects estimates. Columns 1 and 2 use the sample in which siblings were surveyed at the same time in CDS-2. When sibling fixed effects are included, the estimated effect of talking about giving falls to 2.7 percentage points and is not significantly different from zero. The estimate falls closer to zero upon the addition of the controls. Among the control variables, girls are 11.4 percentage points more likely to give than boys. It is not possible to identify role-modeling effect in this specification because almost all sibling pairs are living in the same family unit and consequently each in the pair receives the same role-model. Results from siblings surveyed at the same time in CDS-3 are similar, except that girls are not more likely to give (not shown but available upon request).

In the difference over time between siblings specification in columns 3 and 4 , the estimated effect

\footnotetext{
${ }^{5}$ Estimates of the parent talking and role-modeling coefficients in Table 3 using the weights produces qualitatively similar results. For example, in column 4 the estimates are .103 (.046) and .004 (.052) respectively. For the sibling models, it is not clear which child's weight from the two available in each sibling pair should be used. Therefore to maintain uniformity of presentation across the tables we present the unweighted results.
} 
of talking about giving becomes negative and larger in magnitude, but is imprecisely estimated. Columns 5 and 6 use the sibling pairs in which one sibling is surveyed in CDS-2 and the other sibling in CDS-3: the across-time sibling fixed effects specification. In this specification the estimated effect of talking about giving is positive and the order of magnitude is similar to that in the child fixed effects specification. A role-modeling effect can be estimated in the across-time sibling fixed effect specification, but the estimated effect is negative and insignificant.

From the perspective of the robust role-modeling results in the experimental literature, the absence of a significantly positive role-modeling effect in the child fixed effects and across-time sibling fixed effects specifications is surprising. A possible explanation is measurement error. One approach to address the measurement error problem would be to ask the children what they know about their parents' giving. Unfortunately, the CDS did not include such questions. The best we can do is to consider alternative mappings of the available parental giving data to form alternative role-modeling variables. Table 5 contains the results using the child fixed effects sample. All specifications include the additional controls although the coefficients of socialization actions are the only estimates presented. Column 1 repeats the baseline specification from Table 3 column 4 . In column 2 the parental giving data from the PSID 2003 and 2005 waves are used, along with the 2001 and 2007 waves, to build a role-modeling variable intended to capture more long-term changes in parental giving. To fix ideas, a 0011 pattern (the parents do not give in 2001 and 2003 but do give in both 2005 and 2007) is mapped to a $0 \rightarrow 1$ indicating that the role-model "turns on." While this is no different than how the 0011 parental giving data would have been mapped to the rolemodeling variable in the baseline specification, in column 2 a 1000 is mapped to a $0 \rightarrow 0$ indicating the role-model was "always off." The idea is that the 1000 may indicate parents who, for the most part, do not give and that mapping that pattern to a $1 \rightarrow 0$ as done in the baseline specification introduces a false transition. Similarly, a 1110 pattern is mapped to a $1 \rightarrow 1$ indicating the rolemodel was always on. The full details of the mapping are available in the Appendix. Although the column 2 mapping is somewhat ad hoc, it does provide one approach to check measurement error. The estimated role-modeling effect in column 2 is negative and insignificant. 
Column 3 contains results from a second alternative mapping. We go back to using just the 2001 and 2007 waves for the parental giving data, but split those data to form separate indicators of whether parents give to religious congregations and to secular charitable organizations. The estimated effects of both indicators are small in magnitude and not significant. Column 4 adds the separate log amounts given to consider a mapping in which the size of the amount given drives the role-modeling effect, but once again the estimates are small and not significant. A similar specification adding the log total (religious plus secular) amount given also produces a small, insignificant role-modeling estimate (not shown in the table). In summary, none of the alternative formations of role-modeling variables we tried altered the qualitative result from the baseline specification.

Table 6 presents results from the child fixed effects specification estimated separately for four gender-by-race subsamples. Ottoni-Wilhelm et al. (2011) found gender differences in their crosssectional results, and there are some gender and race differences already emerging in Tables 3 and 4. The results in Table 6 indicate very large effects of parents talking about giving among African-American girls and non-African-American boys. There is a large role-modeling effect among non-African-American girls. Both the talking about giving and role-modeling effects are positive among African-American boys, but smaller in magnitude with standard errors roughly the same magnitude as the point estimates.

\section{Discussion}

We begin by discussing the verbal socialization results. The child fixed effects and across-time sibling fixed effects estimates $\left(\hat{b}^{T}\right.$ and $\left.b^{J D T}\right)$ suggest that talking to children about giving increases the probability that children give by .13. The sibling fixed effects and difference over time between siblings estimates $\left(\hat{b^{J}}\right.$ and $\left.b^{\hat{J} T}\right)$ are not significantly different from zero at conventional levels; assuming that $\beta \geq 0$ these insignificant estimates imply $\beta \approx 0$, that is, to imply that talking to children about giving has zero causal effect. There are two inferences that can be drawn from 
these four estimates regardless of identifying assumptions one makes about parental compensation/reinforcement and cultural substitution/complementarity. First, parents neither compensate nor reinforce differences between their children's prosocial endowments, that is $\gamma_{1}=\gamma_{2}$. Two separate results lead to this conclusion: (a) $\hat{b^{J}}=b^{\hat{J} T}$ and comparing the right-hand sides of equations (14) and (15) and (b) $b^{T}=b^{\hat{J D T}}$ and comparing equations (9) and (16). ${ }^{6}$ Second, and in contrast, parents do socialize child $i$ differently depending upon time-varying changes in child $k$ 's prosocial values, that is $\pi_{2} \neq 0$. This is implied by the result that $b^{T} \neq b^{\hat{J} T}$ and comparing equations (9) and (15).

The implication of $\pi_{2} \neq 0$ is that it is necessary to use the identification framework based on the intra-household allocation and cultural transmission models developed in Section 3 to draw causal inferences from the estimates. We organize our discussion of the inferences that can be drawn from the identification assumptions and the estimates according to the triangles in Figure 1. We begin with the west triangle where the identification assumptions are that parents compensate changes in the difference between their children's prosocial values and that parents view the socialization actions of others as cultural substitutes. Recall that for all $\left(\pi_{1}, \pi_{2}\right)$ pairs in this triangle both $b^{T}$ and $b^{J T}$ are negatively biased. This implies $\operatorname{plim} b^{T}, \operatorname{plim} b^{J T} \leq \beta$. The west triangle is further divided into two sets where either (a) the magnitude of bias $\left(b^{J T}\right)$ is smaller, hence $\operatorname{plim} b^{T}<\operatorname{plim} b^{J T} \leq \beta$ or (b) bias $\left(b^{T}\right)$ is smaller, hence $\operatorname{plim} b^{J T}<\operatorname{plim} b^{T} \leq \beta$. The former is incompatible with our estimates, but the latter is compatible. It follows that holding identifying assumptions of parental compensation combined with cultural substitution leads to an inference from the estimates that the causal effect of talking to children about giving is bounded from below by .13 .

Continuing with the south triangle, the identification assumptions are that parents reinforce changes in the difference between their children's prosocial values and that parents view the socialization actions of others as cultural substitutes. These assumptions are incompatible with the

\footnotetext{
${ }^{6}$ The argument that the evidence implies $\gamma_{1}-\gamma_{2}=0$ is somewhat more involved because while $\gamma_{1}-\gamma_{2}=0$ is a sufficient condition for $b^{J}=b^{J T}$ and for $b^{T}=b^{J D T}$, it is not a necessary condition. Specifically, it can be shown that the alternative to $\gamma_{1}-\gamma_{2}=0$ that would also imply $b^{J}=b^{J T}$ is: $\gamma_{1}-\gamma_{2}=\left(\pi_{1}-\pi_{2}\right)+\sigma_{u}^{2} /\left[\left(\pi_{1}-\pi_{2}\right) \sigma_{\theta}^{2}\right]$. Likewise $\gamma_{1}-\gamma_{2}=\left[\left(\pi_{1}^{2}+\pi_{2}^{2}\right) \sigma_{\theta}^{2}+\sigma_{u}^{2}\right] /\left(\pi_{1} \sigma_{\theta}^{2}\right)$ would also imply $b^{T}=b^{J D T}$. However, if both of these alternatives were true, then $\pi_{1}$ and $\pi_{2}$ would have to satisfy $\left[R-\left(\pi_{1}^{2}-\pi_{2}^{2}\right)\right] \times \pi_{2}=0$. Then equation (17) would imply $b^{T}=b^{J T}$, which is not compatible with our estimates.
} 
estimates. The quadrant 3 portion of the triangle is ruled out because there the bias $\left(b^{T}\right)$ is negative and the $\operatorname{bias}\left(b^{J T}\right)$ is positive - $\operatorname{plim} b^{T}<\beta<\operatorname{plim} b^{J T}$ - but this is contradicted by the estimation result that $b^{T}>b^{\hat{J} T}$. In the quadrant 2 portion of the south triangle, both biases are positive and $b^{T}$ is the least biased estimator- $\beta<\operatorname{plim} b^{T}<\operatorname{plim} b^{J T}$ - but again this is contradicted by the result $\hat{b^{T}}>b^{\hat{J} T}$.

In the east triangle the identification assumptions are reinforcement combined with cultural complementarity, and both $b^{T}$ and $b^{J T}$ are positively biased. The two areas in the east triangle in which $b^{T}$ is the least biased estimator are ruled-out because in these areas $\beta<\operatorname{plim} b^{T}<$ plim $b^{J T}$ but again $b^{T}>b^{\hat{J} T}$. This leaves the two areas in which $b^{J T}$ is the least biased estimator. The identification assumptions in these areas are either (a) relatively weak reinforcement but relatively strong cultural complementarity $\left(\pi_{1}>0, \pi_{2}>0\right)$ or (b) relatively strong reinforcement but relatively weaker cultural complementarity $\left(\pi_{1}>0, \pi_{2}<0\right)$ plus overall strong parental responsiveness to changes in their children's prosocial values $\left(\pi_{1}^{2}+\pi_{2}^{2}>R\right)$. If either assumption (a) or (b) is held, $b^{J T}$ is if anything positively biased. Consequently the inference from $b^{\hat{J} T}$ being insignificantly different from zero would be that there is zero causal effect of talking to children about giving. The same inference follows from the identification assumptions at the northern edge of the east triangle (the $\pi_{1}=\pi_{2}$ line): parents neither compensate nor reinforce differences that arise because of changes in their children's prosocial values (the sibling fixed effects estimator is unbiased) and parents view the socialization actions of others as very strong cultural complements.

In the north triangle the identification assumptions are compensation combined with cultural complementarity. In the quadrant 1 portion of the triangle consider $\left(\pi_{1}, \pi_{2}\right)$ pairs along a circle of radius $\sqrt{S}$. The $\left(\pi_{1}, \pi_{2}\right)$ pairs on the circle closer to the $\pi_{1}=\pi_{2}$ line correspond to relatively weak compensation but relatively strong cultural complementarity. Also, for all the $\left(\pi_{1}, \pi_{2}\right)$ pairs on the circle (in quadrant 1), bias $\left(b^{J T}\right)$ is negative and bias $\left(b^{T}\right)$ is positive: $\operatorname{plim} b^{J T}<\beta<\operatorname{plim} b^{T}$. At $\pi_{1}=\pi_{2}$ the estimator $b^{J T}$ is unbiased. Moving counterclockwise on the circle from where the circle intersects the $\pi_{1}=\pi_{2}$ line, the $\left(\pi_{1}, \pi_{2}\right)$ pairs are those for which bias $\left(b^{T}\right)>\operatorname{bias}\left(b^{J T}\right)$. When the circle intersects the equal bias boundary bias $\left(b^{T}\right)=\operatorname{bias}\left(b^{J T}\right)$. Continuing counterclockwise 
$0<\left|\operatorname{bias}\left(b^{T}\right)\right|<\left|\operatorname{bias}\left(b^{J T}\right)\right|$ until the $\pi_{2}$ axis is reached, at which $b^{T}$ is unbiased (because $\pi_{1}=0$ ). Replacing the probability limits with the estimates, the counterclockwise movement along the circle implies values of $\beta$ from zero (at $\pi_{1}=\pi_{2}$ ) to .13 (at the $\pi_{2}$ axis) with $\beta=.065$ at the equal bias boundary (because at the boundary $\beta$ must be in the middle of the two estimates). Hence, identifying assumptions that parents compensate changes in their children's prosocial values, but relatively weakly, and that parents view the socialization actions of others as relatively strong cultural complements, lead to an inference from the estimates that $\beta$ is bounded by $[0, .13]$, with values in the lower part of this interval implied by relatively weaker compensation/stronger complementarity.

Continuing on the circle but entering the quadrant 4 portion of the north triangle the $\left(\pi_{1}, \pi_{2}\right)$ pairs correspond to relatively stronger compensation and relatively weaker cultural complementarity. Also, for all the $\left(\pi_{1}, \pi_{2}\right)$ pairs both $b^{T}$ and $b^{J T}$ are negatively biased, and the magnitude of $\operatorname{bias}\left(b^{T}\right)$ is smaller: $\operatorname{plim} b^{J T}<\operatorname{plim} b^{T} \leq \beta$. Hence, identifying assumptions of relatively strong compensation and relatively weak complementarity leads to the inference that $\beta$ is bounded from below by .13.

To summarize, in order to infer that there is zero causal effect of talking to children about giving, it would be necessary to maintain an identifying assumption of cultural complementarity in the socialization of giving. More precisely, it would be necessary to maintain that there is either (a) strong cultural complementarity plus reinforcement of within-sibling changes in prosocial valuesor if not reinforcement only very weak compensation, or (b) weaker complementarity but which is necessarily combined with strong reinforcement of within-sibling changes plus overall strong parental responsiveness to the changes. In contrast, inferring a positive causal effect requires an identifying assumption of either (c) cultural substitution or (d) complementarity combined with stronger (than in (a)) compensation of within-sibling changes in prosocial values. The pattern of estimates rules out substitution combined with reinforcement. Therefore, the cultural substitution identifying assumption, combined with the pattern of estimates, implies compensation of changes in the difference between children's prosocial values. The inference that follows would be that the 
causal effect of talking to children about giving is bounded from below by .13. A positive causal effect also would follow from cultural complementarity as long as compensation was not too weak.

Moving to the role-modeling results, the child fixed effects estimates taken at face value imply a zero causal effect of role-modeling. The face value interpretation has some credibility because it is the child fixed effects specification (as well as the difference over time between siblings specification) that provides the empirical basis for inferring a positive causal effect of verbal socialization. Nevertheless, there are three counter-arguments. First, if a parent views exogenous changes in her child's prosocial values as substitutes for her own role-modeling then $\operatorname{bias}\left(b^{T}\right)$ would be negative, and $\hat{b^{T}} \approx 0$ would be compatible with a positive role-modeling effect. However, a parent's giving likely is influenced by many considerations other than changes in her child's prosocial values. If so then the magnitude of $\pi_{1}$ for the role-modeling action likely is smaller than the magnitude of $\pi_{1}$ (and $\pi_{2}$ ) for the talking action, implying that any biases in $b^{T}$ for role-modeling would be smaller than for talking. Taking the position that a parent's giving is strongly influenced by changes in her child's prosocial values also would imply a strongly instrumental view of giving narrowly focused on children's socialization.

The second counter-argument is that the role-modeling estimate could be biased toward zero by measurement error. We examined numerous alternative ways to construct the role-modeling variable, and for all of them $b^{T}$ was not significantly different from zero. It could be that all these alternative constructions suffer from a kind of measurement error that children do not know what, or even whether, parents are giving, so that even though a role-model is transmitted by parents it is not seen by children. This kind of measurement error could explain the $b^{T} \approx 0$ result, but carries with it an important substantive implication: parents are wasting a potentially effective way to raise charitable children by not taking steps to ensure their role-model of giving is seen by their children. Furthermore, for non-African-American girls role-modeling is estimated to have a large, statistically significant positive effect. This result works against a measurement error argument, and is in itself of substantive interest.

The third counter-argument is that it could be that regular parental giving across the years 
has a role-modeling effect in raising children who themselves become regular givers. That there is a strong association between regular parent giving and regular child giving in the child fixed effects sample supports this conjecture. ${ }^{7}$ Unfortunately, data that could be used to estimate the relationship between changes in parents' regular giving and their children's regular giving do not exist. It is important to point out that, if the causal effect of role-modeling resides in parents modeling regular giving, this is not the kind of role-modeling effect measured by the laboratory experiments in developmental psychology.

Although this paper has made important progress in estimating the effects of verbal socialization and role-modeling, there are questions that remain unanswered. An important question is about the nature of the talking the parents are doing. For instance, most experiments have found that empathy-based, other-oriented induction - emphasizing to the child the positive effect giving will have on the emotional well-being of people to be helped-has a positive effect on children's giving (Dlugokinski and Firestone 1974; Eisenberg-Berg and Geisheker 1979; Grusec et al. 1978). However, we do not know how frequently parents use other-oriented induction compared to, say, conversations that are duty-based (e.g., "giving is the right thing to do") or self-based (e.g., "if you give you will feel good"). Another important question is about the effectiveness of verbal socialization and role-modeling on children's separate giving to secular organizations and religious congregations, and on the amounts children give. Data do not exist to investigate either the nature of talking question or the questions about disaggregated children's giving. Collecting such data is an important direction for future research.

Finally, if we had some evidence about $\pi_{1}$ and $\pi_{2}$, even their signs, we would be able to rule out additional identifying assumptions as incompatible with the evidence about verbal socialization. This also is an important topic for future research. Until then we draw our conclusions based on the identifying assumption we think is most reasonable: that parents treat the socialization actions of others as cultural substitutes. We favor this identifying assumption for two reasons that draw on core arguments from the intra-household allocation and cultural transmission literatures. Drawing

\footnotetext{
${ }^{7}$ In a specification that follows Table 3 column 2, the probability that the child gives in both years is 12.6 percentage points higher $($ s.e. $=.041$ ) if the parent gives in three or four years out of 2001, 2003, 2005, and 2007.
} 
on the intra-household allocation literature, assuming that the uses of parental time to achieve other socialization goals are normal goods, a Becker and Tomes (1979) family income argument implies that when a child's prosocial values increase because of the socialization of others, the parent will reduce her socialization of giving somewhat so that she can spend more time achieving other socialization goals. The counter-assumption of complementarity would require either that some other uses of parental time are non-normal goods, or perhaps a bounded rationality argument that increases in the child's prosocial values bring the goal of socializing giving to the forefront of the parent's mind and she in turn talks more about giving to her child. Drawing on the cultural transmission literature, that giving is heterogeneous in the population suggests cultural substitution, or at a minimum cultural complementarity that is not strong. In addition, the cultural substitution identifying assumption combined with the pattern of estimates implies that parents compensate within-sibling changes in prosocial values, consistent with thinking in child development about parental responses to within-sibling differences (Thomas and Chess 1977). Under an identifying assumption of cultural substitution, or weak cultural complementarity, the estimates imply that the causal effect of verbal socialization on the probability that children give to charity is at least .13 .

\section{Conclusion}

This paper provides the first estimates of the effects of verbal socialization and role-modeling on children's charitable giving based on nationally-representative data from children in their home settings. A second contribution is that we develop a framework useful for identifying causal effects of parental socialization or investment actions on children's outcomes when there is timevarying unobserved heterogeneity in the outcome equation correlated with the actions parents take. The framework shows how bounds on the causal effects of parent socialization actions can be inferred from within-child and within-siblings estimates combined with identifying assumptions about how parents respond to time-varying unobserved heterogeneity. The identifying assumptions 
are characterized using constructs from the well-known economic literatures on intra-household allocation and cultural transmission.

Applying this framework to parental socialization of children's charitable giving, the pattern of estimates indicates that parents socialize a child differently depending upon changes in his/her sibling's prosocial values. Under the identifying assumption we think is most reasonable - that parents treat the socialization actions of others as cultural substitutes - our estimates imply that talking to children about giving raises the probability they give by at least .13. Surprisingly, in light of the developmental psychology experiments, our estimates based on the full sample of children indicate no evidence that parents' role-model of giving has a causal effect on children's giving.

However, when we examine demographic sub-groups of children we find that role-modeling increases the probability that non-African-American girls give to charity by .14. The effect of talking about giving also differs by demographic group: .07 (not statistically significant) for nonAfrican-American girls, .18 for African-American girls and .22 for non-African-American boys. The estimated effects of verbal socialization and role-modeling are positive for African-American boys (.08 and .06) but not statistically significant. To our knowledge these are the first estimates, even among results from the experimental papers, of the effectiveness of verbal socialization and role-modeling separately by demographic group.

The results have three implications. First, parents whose goal is to raise charitable children should continue, not curtail, conversations about giving as their children age through adolescence. This is important because in our child fixed effects sample, 16 percent of the children have parents who stopped talking to them about giving as the children got older. Second, translational research is needed to learn how role-modeling, known to be effective in the laboratory, can be used effectively in the home. Finally, the identification framework we develop is generally applicable in applications having child and sibling fixed effects data that include measurement of parents' socialization and/or investment actions. Data on socialization/investment actions of those other than parents, or proxies for these actions, are necessary to further narrow down the range of intra-household and 
cultural transmission identifying assumptions compatible with the estimates. In turn this would narrow down the range of causal effects compatible with estimates from child and sibling fixed effects models. 


\section{References}

[1] Altonji, Joseph G. and Thomas A. Dunn. (1996a). Using Siblings to Estimate the Effect of School Quality on Wages. Review of Economics and Statistics, 78(4), 665-671.

[2] Altonji, Joseph G. and Thomas A. Dunn. (1996b). The Effect of Family Characteristics on the Return to Education. Review of Economics and Statistics, 78(4), 692-704.

[3] Becker, Gary S. and Nigel Tomes. (1976). Child Endowments and the Quantity and Quality of Children. Journal of Political Economy, 84(4, Part 2), S143-S162.

[4] Becker, Gary S. and Nigel Tomes. (1979). An Equilibrium Theory of the Distribution of Income and Intergenerational Mobility. Journal of Political Economy, 87(6), 1153-1189.

[5] Behrman, Jere, R. Mark R. Rosenzweig, and Paul Taubman. (1994). Endowments and the Allocation of Schooling in the Family and in the Marriage Market: The Twins Experiment. Journal of Political Economy, 102(6), 1131-1174.

[6] Berk, Laura E. (2003). Child Development, Sixth edition. Boston, MA: Allyn and Bacon.

[7] Bisin, Alberto and Thierry Verdier. (2001). The Economics of Cultural Transmission and the Dynamics of Preferences. Journal of Economic Theory, 97, 298-319.

[8] Bisin, Alberto and Thierry Verdier. (2011). The Economics of Cultural Transmission and Socialization. In Jess Benhabib, Alberto Bisin, and Matthew O. Jackson, eds., Handbook of Social Economics, Volume 1A. Amsterdam: North-Holland.

[9] Brown, Sarah, Preety Srivastava, and Karl Taylor. (2012). Preach What you Practice? Donating Behavior of Parents and Their Offspring. Sheffield Economic Research Paper Series No. 2012018. Sheffield, UK: Department of Economics, University of Sheffield.

[10] Bryan, James H. and Nancy H. Walbek. (1970). The Impact of Words and Deeds Concering Altruism Upon Children. Child Development, 41(3), 747-757. 
[11] Dlugokinski, Eric L. and Ira J. Firestone. (1974). Other Centeredness and Susceptibility to Charitable Appeals: Effects of Perceived Discipline. Developmental Psychology, 10, 21-28.

[12] Dressel, Susan and Elizabeth Midlarsky. (1978). The Effect of Model's Exhortations, Demands, and Practices on Children's Donation Behavior. Journal of Genetic Psychology, 132(2), 211-223.

[13] Eisenberg, Nancy. (1990). Prosocial Development in Early and Mid-adolescence. In R. Montemayor, G. R. Adams, and T. P. Gullota, eds., From Childhood to Adolescence: A Transitional Period (Advances in Adolescent Development). Newbury Park, CA: Sage.

[14] Eisenberg, Nancy and Richard A. Fabes. (1998). Prosocial Development. In Nancy Eisenberg, eds., Handbook of Child Psychology, Volume 3 (5th edition). New York: Wiley.

[15] Eisenberg, Nancy, Richard A. Fabes, and Tracy L. Spinrad. (2006). Prosocial Development. In Nancy Eisenberg and William Damon, eds., Handbook of Child Psychology, Volume 3 (6th edition). New York: Wiley.

[16] Eisenberg, Nancy and Paul H. Mussen. (1989). The Roots of Prosocial Behavior in Children. Cambridge: Cambridge University Press.

[17] Eisenberg-Berg, Nancy and Elizabeth Geisheker. (1979). Content of Preaching and Power of the Model/Preacher: The Effect on Children's Generosity. Developmental Psychology, 15, $168-175$.

[18] Ermisch, John F. and Marco Francesoni. (2001). Family Structure and Children's Achievements. Journal of Population Economics, 14, 249-270.

[19] Gallo, Eileen and John Gallo. (2001). Silver Spoon Kids: How Successful Parents Raise Responsible Children. New York: Contemporary Books.

[20] Geronimus, Arline T. and Sanders Korenman. (1992). The Socioeconomic Consequences of Teen Childbearing Reconsidered. Quarterly Journal of Economics, 107(4), 1187-1214. 
[21] Grusec, Joan E., Peter Saas-Kortsaak, and Zita M. Simutis. (1978). The Role of Example and Moral Exhortation in the Training of Altruism. Child Development, 49, 920-923.

[22] Israel, Allen C. and Margary S. Brown. (1979). Effects of Directiveness of Instructions and Surveillance on the Production and Persistence of Children's Donations. Journal of Experimental Child Psychology, 27(2), 250-261.

[23] Israel, Allen C. and Pamela A. Raskin. (1979). Directiveness of Instructions and Modeling: Effects on Production and Persistence of Children's Donations. Journal of Genetic Psychology, 135(2), 269-277.

[24] Levine, Phillip B., Tara A. Gustafson, and Ann D. Velenchik. (19970. More Bad News for Smokers? The Effects of Cigarette Smoking on Labor Market Outcomes. Industrial and Labor Relations Review, 50(3), 493-509.

[25] Lipscomb, Thomas J., Norman J. Bregman, and Hunter A. McAllister. (1983). The Effects of Words and Actions on American Children's Prosocial Behavior. Journal of Psychology, 114, 193-198.

[26] McGrath, Marianne P., Steven R. Wilson and Sandra J. Frassetto. (1995). Why Some Forms of Induction Are Better Than Others at Encouraging Prosocial Behavior. Merrill-Palmer Quarterly, 41, 347-360.

[27] Perry, David G., Kay Bussey, and Kathryn Freiberg. (1981). Impact of Adults' Appeals for Sharing on the Development of Altruistic Dispositions in Children. Journal of Experimental Child Psychology, 32, 127-138.

[28] Ottoni-Wilhelm, Mark, David B. Estell, and Neil H. Purdue. (2011). Role-modeling and Conversation about Giving in the Socialization of Adolescent Charitable Giving and Volunteering. Working Paper, Indiana University-Purdue University Indianapolis.

[29] Owens, Charles R. and Frank R. Ascione. (1991). Effects of Model's Age, Perceived Similarity, and Familiarity on Children's Donating. Journal of Genetic Psychology, 153(3), 341-357. 
[30] Ribar, David C. (1999). The Socioeconomic Consequences of Young Women's Childbearing: Reconciling Disparate Evidence. Journal of Population Economics, 12(4), 547-565.

[31] Rice, Marnie E. and Joan E. Grusec. (1975). Saying and Doing: Effects on Observer Performance. Journal of Personality and Social Psychology, 32(4), 584-593.

[32] Rosenzweig, Mark R. and Kenneth I. Wolpin. (1995). Sisters, Siblings, and Mothers: The Effect of Teen-Age Childbearing on Birth Outcomes in a Dynamic Family Context. Econometrica, 63(2), 303-326.

[33] Rushton, J. Philippe. (1975). Generosity in Children: Immediate and Long-Term Effects of Modeling, Preaching, and Moral Judgment. Journal of Personality and Social Psychology, 31(3), 459-466.

[34] Smith, Cathleen L., Mary D. Leinbach, Barbara J. Stewart, and Jane M. Blackwell. (1983). Affective Perspective-Taking, Exhortations, and Children's Prosocial Behavior. In Diane L. Bridgeman, eds., The Nature of Prosocial Development. New York: Academic Press.

[35] Thomas, Alexander and Stella Chess. (1977). Temperament and Development. New York: Brunner/Mazel.

[36] Weisman, Carol. (2006). Raising Charitable Children. St. Louis, MO: F. E. Robbins and Sons Press.

[37] White, Glenn M. and M. Audrey Burnam. (1975). Socially Cued Altruism: Effects of Modeling, Instructions, and Age on Public and Private Donations. Child Development, 46, 559-563.

[38] Wilhelm, Mark O. and Bekkers, Rene. (2010). Helping Behavior, Dispositional Empathic Concern, and the Principle of Care. Social Psychology Quarterly 73(1), 11-32. 


\section{Appendix}

Alternative Specification of Role-Modeling Variable with Parental Giving Data from PSID 2001, 2003, 2005, and 2007

\begin{tabular}{|c|c|}
\hline $\begin{array}{c}\text { Observed Parental Giving Pattern in } \\
\text { PSID 2001, 2003, 2005 and 2007 }\end{array}$ & Role-Modeling Variable \\
\hline 0000 & $0 \rightarrow 0$ \\
\hline 0001 & $0 \rightarrow 0$ \\
\hline 0010 & $0 \rightarrow 0$ \\
\hline 0011 & $0 \rightarrow 1$ \\
\hline 0100 & $0 \rightarrow 0$ \\
\hline 0101 & $0 \rightarrow 1$ \\
\hline 0110 & $0 \rightarrow 0$ \\
\hline 0111 & $1 \rightarrow 1$ \\
\hline 1000 & $0 \rightarrow 0$ \\
\hline 1001 & $1 \rightarrow 1$ \\
\hline 1010 & $1 \rightarrow 0$ \\
\hline 1011 & $1 \rightarrow 1$ \\
\hline 1100 & $1 \rightarrow 0$ \\
\hline 1101 & $1 \rightarrow 1$ \\
\hline 1110 & $1 \rightarrow 1$ \\
\hline 1111 & $1 \rightarrow 1$ \\
\hline
\end{tabular}


Figure 1. Identifying Assumptions about $\pi_{1}$ and $\pi_{2}$ and Bias in $b^{T}$ and $b^{J T}$

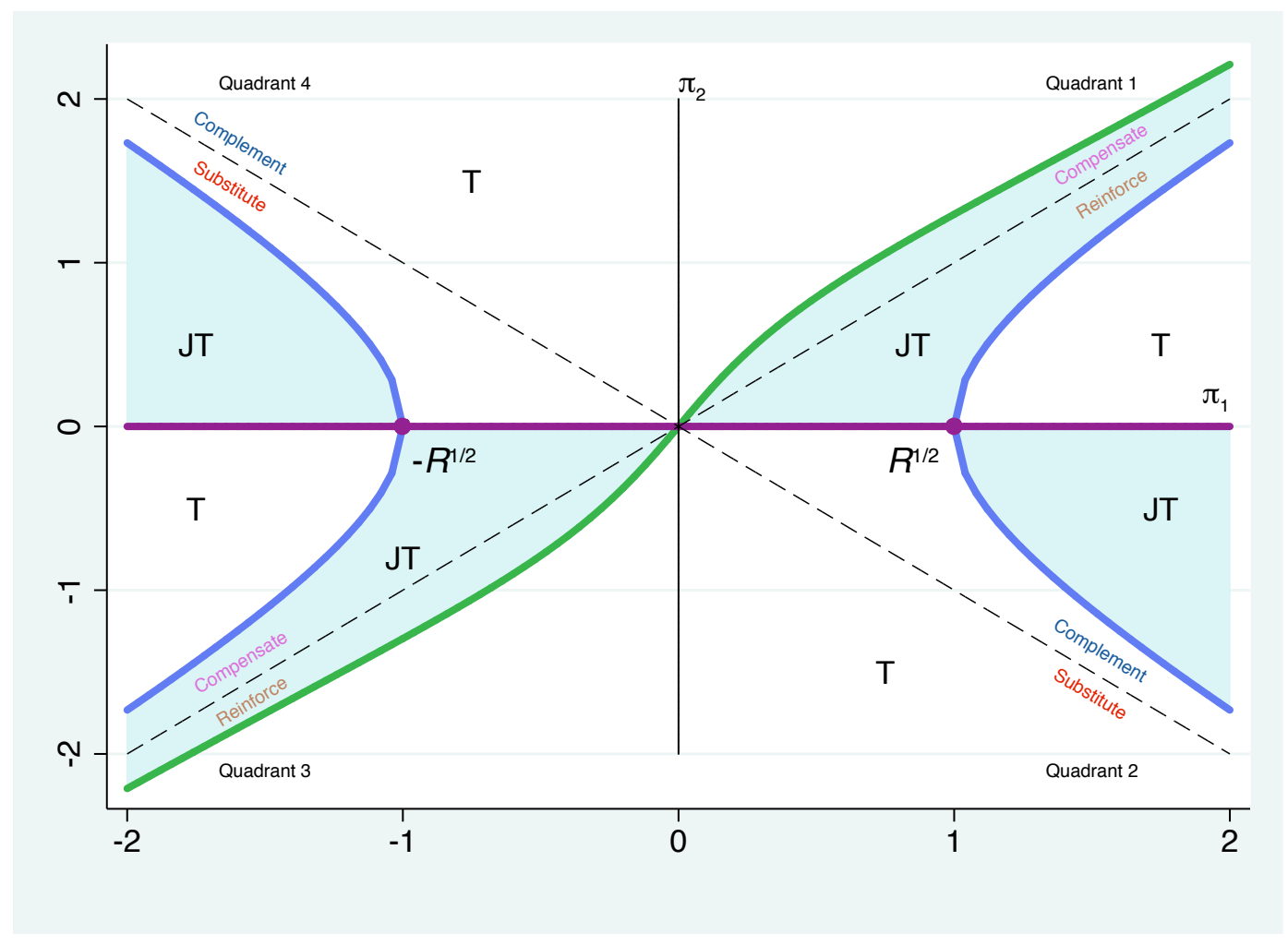

Notes: 1 . On the three equal bias boundaries (blue, green, and purple) $\left|\operatorname{bias}\left(b^{T}\right)\right|=\left|\operatorname{bias}\left(b^{J T}\right)\right|$. In the shaded JT areas $\left|\operatorname{bias}\left(b^{T}\right)\right|>\left|\operatorname{bias}\left(b^{J T}\right)\right|$.

In the white $\mathrm{T}$ areas $\left|\operatorname{bias}\left(b^{T}\right)\right|<\left|\operatorname{bias}\left(b^{J T}\right)\right|$.

2. Directions of bias:

Quadrant 1 north of the $\pi_{2}=\pi_{1}$ line: $\operatorname{bias}\left(b^{T}\right)$ is positive and $\operatorname{bias}\left(b^{J T}\right)$ is negative.

Quadrant 1 south of the $\pi_{2}=\pi_{1}$ line and Quadrant 2: $\operatorname{bias}\left(b^{T}\right)$ is positive and $\operatorname{bias}\left(b^{J T}\right)$ is positive.

Quadrant 3 south of the $\pi_{2}=\pi_{1}$ line: $\operatorname{bias}\left(b^{T}\right)$ is negative and bias $\left(b^{J T}\right)$ is positive.

Quadrant 3 north of the $\pi_{2}=\pi_{1}$ line and Quadrant 4: $\operatorname{bias}\left(b^{T}\right)$ is negative and $\operatorname{bias}\left(b^{J T}\right)$ is negative.

3. $R=\frac{\sigma_{u}^{2}}{\sigma_{\theta}^{2}}$. 
Table 1. Descriptive Statistics for the Three Analysis Samples

\begin{tabular}{lccc}
\hline \hline Variables & $\begin{array}{c}\text { Child Fixed } \\
\text { Effects Sample }\end{array}$ & $\begin{array}{c}\text { Sibling Fixed } \\
\text { Effects Sample }\end{array}$ & $\begin{array}{c}\text { Across-time Sibling } \\
\text { Fixed Effects Sample }\end{array}$ \\
\hline Giving & 0.714 & 0.700 & 0.701 \\
Parent talks about giving & 0.718 & 0.659 & 0.683 \\
Role-modeling: parent gives & 0.684 & 0.726 & 0.645 \\
Age & 13.2 & 13.3 & 13.9 \\
Female & $(3.0)$ & $(2.8)$ & $(2.6)$ \\
African-American & 0.474 & 0.516 & 0.512 \\
Intact family & 0.173 & 0.175 & 0.153 \\
Female headed & 0.646 & 0.671 & 0.668 \\
Family moved & 0.218 & 0.196 & 0.199 \\
Family income & 0.252 & 0.244 & 0.245 \\
(\$1000s) & 82.112 & 80.461 & 82.582 \\
Child income & $(89.204)$ & $(121.914)$ & $(89.170)$ \\
(\$1000s) & 0.535 & 0.606 & 0.622 \\
Child savings & $(1.408)$ & $(1.575)$ & $(1.675)$ \\
(\$1000s) & 0.4 & 0.387 & 0.53 \\
Parental warmth & $(1.861)$ & $(2.189)$ & $(2.450)$ \\
Reading score & 2.666 & 2.823 & 2.605 \\
Math score & $(0.733)$ & $(0.688)$ & $(0.700)$ \\
Sample size & 104 & 104 & 104 \\
Number of children (col. 1) / & $(17)$ & $(18)$ & $(18)$ \\
sibling pairs (cols. 2 and 3) & 107 & 105 & 106 \\
\hline \hline Source: Authors & $(17)$ & $(16)$ \\
& $(17)$ & 1,152 & 1,041 \\
& 1,872 & 576 & 521 \\
\hline
\end{tabular}

Source: Authors' calculations from PSID and CDS samples.

Notes: 1. The sample in column 1 are those aged 8 and older in CDS-2 who where also young enough to still be in CDS-3. The sample in column 2 are sibling pairs in CDS-2. The sample in column 3 are sibling pairs in which the older sibling was in CDS-2 and the younger sibling was in CDS-3. Standard deviations for continuous variables are in parentheses.

a: Lives with birth-mother only or with step-mother only. 
Table 2. Within-Variation in the Three Analysis Samples

\begin{tabular}{|c|c|c|c|c|c|}
\hline \multicolumn{6}{|c|}{ Panel A: Child Fixed Effects Sample } \\
\hline \multirow{5}{*}{ Standard deviation } & & Child's giving & $\begin{array}{l}\text { Parent talks } \\
\text { about giving }\end{array}$ & Parents gives & Log family income \\
\hline & Total & 0.444 & 0.448 & 0.484 & 1.136 \\
\hline & Between-child & 0.346 & 0.361 & 0.409 & 1.012 \\
\hline & Within-child & 0.279 & 0.265 & 0.259 & 0.517 \\
\hline & $\begin{array}{l}\text { Percentage of variance } \\
\text { within-child }\end{array}$ & $39 \%$ & $35 \%$ & $29 \%$ & $21 \%$ \\
\hline \multirow{4}{*}{$\begin{array}{l}\text { Within-child transitions } \\
\text { across time }\end{array}$} & $0 \rightarrow 0$ & 0.115 & 0.137 & 0.239 & - \\
\hline & $1 \rightarrow 0$ & 0.134 & 0.164 & 0.138 & - \\
\hline & $0 \rightarrow 1$ & 0.177 & 0.116 & 0.130 & - \\
\hline & $1 \rightarrow 1$ & 0.574 & 0.583 & 0.493 & - \\
\hline
\end{tabular}

Panel B: Sibling Fixed Effects Sample

\begin{tabular}{|c|c|c|c|c|c|}
\hline \multicolumn{6}{|c|}{ Panel B: Sibling Fixed Effects Sample } \\
\hline & & Child's giving & $\begin{array}{l}\text { Parent talks } \\
\text { about giving }\end{array}$ & Parent gives ${ }^{\mathrm{a}}$ & Log family income \\
\hline \multirow[t]{4}{*}{ Standard deviation } & Total & 0.449 & 0.463 & - & - \\
\hline & Between-sibling pairs & 0.353 & 0.427 & - & - \\
\hline & Within-sibling pairs & 0.277 & 0.179 & - & - \\
\hline & $\begin{array}{l}\text { Percentage of variance } \\
\text { within-sibling pairs }\end{array}$ & $38 \%$ & $15 \%$ & - & - \\
\hline \multirow[t]{4}{*}{ Within-sibling differences ${ }^{b}$} & $0-0$ & 0.127 & 0.247 & - & - \\
\hline & $1-0$ & 0.149 & 0.075 & - & - \\
\hline & $0-1$ & 0.156 & 0.054 & - & - \\
\hline & $1-1$ & 0.568 & 0.625 & - & - \\
\hline
\end{tabular}


Panel C: Across-time Sibling Fixed Effects Sample

$$
\text { Child's giving } \begin{gathered}
\text { Parent talks } \\
\text { about giving }
\end{gathered} \text { Parent gives }{ }^{\mathrm{a}} \quad \text { Log family income }
$$

Standard deviation

Within-sibling differences

across time

\section{Total}

Between-sibling pairs

Within-sibling pairs

Percentage of variance

within-sibling pairs

$\begin{array}{cc}0.451 & 0.456 \\ 0.338 & 0.372 \\ 0.299 & 0.264 \\ 44 \% & 34 \% \\ & \\ & \\ 0.106 & 0.156 \\ 0.177 & 0.144 \\ 0.18 & 0.134 \\ 0.537 & 0.566\end{array}$

0.485

1.072

0.421

0.935

0.241

0.524

$0-0$

$1-0$

$0-1$

$1-1$

0.537

0.566

$25 \%$

$24 \%$

Source: Authors' calculations from PSID and CDS samples.

Notes: 1 . Panel A contains $\mathrm{n}=903$ children who have no missing data in either year that we use to estimate the child fixed-effects model with all the controls. Panel B contains the $\mathrm{n}=576$ sibling pairs in the sibling fixed-effects sample (CDS-2). Panel C contains the $\mathrm{n}=521$ sibling pairs in the across-time sibling fixed-effects sample. The statistics are not weighted.

a: Because almost all siblings reside in the same household there is virtually no within-sibling pair variation in parent's giving.

${ }^{b}$ : The siblings are ordered so that the youngest sibling comes first. For example, $1-0$ in column 3 means that the younger sibling gives but the older sibling does not in 13.4 percent of the CDS-2 sibling pairs.

c: The siblings are ordered so that the older (born first) sibling in CDS-2 comes first. For example, $1-0$ in column 3 means that the older sibling gave (at the time of CDS-2) but the younger sibling did not (at the time of CDS-3) in 14.9 percent of the sibling pairs. 
Table 3. Cross-sectional and Within-child Estimates of Effects of Verbal Socialization and Role-modeling

\begin{tabular}{|c|c|c|c|c|}
\hline \multirow[b]{3}{*}{ Parent talks about giving } & \multicolumn{4}{|c|}{ Dependent Variable: Child's Giving } \\
\hline & \multicolumn{2}{|c|}{ OLS } & \multicolumn{2}{|c|}{ Child FE } \\
\hline & $\begin{array}{c}0.135 * * * \\
(0.025)\end{array}$ & $\begin{array}{c}0.119 * * * \\
(0.026)\end{array}$ & $\begin{array}{c}0.131 * * * \\
(0.036)\end{array}$ & $\begin{array}{c}0.128 * * * \\
(0.037)\end{array}$ \\
\hline Role-modeling: parent gives & $\begin{array}{c}0.062 * * * \\
(0.022)\end{array}$ & $\begin{array}{c}0.064 * * \\
(0.025)\end{array}$ & $\begin{array}{l}-0.005 \\
(0.037)\end{array}$ & $\begin{array}{l}-0.004 \\
(0.038)\end{array}$ \\
\hline Age & & $\begin{array}{l}-0.003 \\
(0.008)\end{array}$ & & \\
\hline Female & & $\begin{array}{c}0.054 * * \\
(0.022)\end{array}$ & & \\
\hline African-American & & $\begin{array}{c}0.112 * * * \\
(0.027)\end{array}$ & & \\
\hline Intact family & & $\begin{array}{c}0.010 \\
(0.033)\end{array}$ & & $\begin{array}{l}-0.087 \\
(0.100)\end{array}$ \\
\hline Female headed & & $\begin{array}{c}-0.060 * \\
(0.034)\end{array}$ & & $\begin{array}{c}-0.054 \\
(0.079)\end{array}$ \\
\hline Family moved & & $\begin{array}{c}-0.004 \\
(0.023)\end{array}$ & & $\begin{array}{c}0.002 \\
(0.034)\end{array}$ \\
\hline Log family income & & $\begin{array}{c}0.004 \\
(0.014)\end{array}$ & & $\begin{array}{c}0.005 \\
(0.027)\end{array}$ \\
\hline Log child's income & & $\begin{array}{c}0.001 \\
(0.014)\end{array}$ & & $\begin{array}{l}-0.001 \\
(0.018)\end{array}$ \\
\hline Log child's savings & & $\begin{array}{c}-0.004 \\
(0.010)\end{array}$ & & $\begin{array}{c}-0.011 \\
(0.012)\end{array}$ \\
\hline Parental warmth & & $\begin{array}{c}0.004 \\
(0.016)\end{array}$ & & $\begin{array}{c}0.013 \\
(0.030)\end{array}$ \\
\hline Reading score & & $\begin{array}{c}0.000 \\
(0.001)\end{array}$ & & $\begin{array}{c}0.001 \\
(0.002)\end{array}$ \\
\hline Math score & & $\begin{array}{l}0.002 * \\
(0.001)\end{array}$ & & $\begin{array}{c}0.002 \\
(0.002)\end{array}$ \\
\hline Observations & 1,858 & 1,839 & 1,806 & 1,806 \\
\hline
\end{tabular}

Source: Authors' calculations from PSID and CDS samples.

Notes: 1. Different numbers of observations for columns are due to missing values on some of the independent variables, results do not change if all the regressions are based on the smallest sample.

2. Robust standard errors clusted at individual level are in parentheses.

3. *** $\mathrm{p}<0.01, * * \mathrm{p}<0.05, * \mathrm{p}<0.1$

4. All regressions include a year dummy. 
Table 4. Different Types of Within-sibling Estimates of the Effects of Verbal Socialization and Role-modeling

\begin{tabular}{|c|c|c|c|c|c|c|}
\hline \multirow[b]{3}{*}{ Parent talks about giving } & \multicolumn{6}{|c|}{ Dependent Variable: Child's Giving } \\
\hline & \multicolumn{2}{|c|}{ Sibling FE } & \multicolumn{2}{|c|}{$\begin{array}{c}\text { Difference Over Time } \\
\text { Between Siblings }\end{array}$} & \multicolumn{2}{|c|}{$\begin{array}{c}\text { Across-time Sibling } \\
\text { FE }\end{array}$} \\
\hline & $\begin{array}{c}0.027 \\
(0.074)\end{array}$ & $\begin{array}{c}0.007 \\
(0.070)\end{array}$ & $\begin{array}{l}-0.067 \\
(0.149)\end{array}$ & $\begin{array}{l}-0.120 \\
(0.147)\end{array}$ & $\begin{array}{c}0.142 * * * \\
(0.048)\end{array}$ & $\begin{array}{l}0.125 * * \\
(0.050)\end{array}$ \\
\hline Role-modeling: parent gives & & & & & $\begin{array}{l}-0.068 \\
(0.056)\end{array}$ & $\begin{array}{l}-0.061 \\
(0.055)\end{array}$ \\
\hline Age & & $\begin{array}{c}0.008 \\
(0.009)\end{array}$ & & & & $\begin{array}{l}-0.009 \\
(0.014)\end{array}$ \\
\hline Female & & $\begin{array}{c}0.114 * * * \\
(0.036)\end{array}$ & & & & $\begin{array}{c}0.008 \\
(0.038)\end{array}$ \\
\hline Intact family & & & & & & $\begin{array}{c}0.133 \\
(0.113)\end{array}$ \\
\hline Female headed & & & & & & $\begin{array}{l}0.224 * * \\
(0.096)\end{array}$ \\
\hline Family moved & & & & & & $\begin{array}{l}-0.029 \\
(0.042)\end{array}$ \\
\hline Log family income & & & & & & $\begin{array}{c}0.005 \\
(0.035)\end{array}$ \\
\hline Log child's income & & $\begin{array}{c}0.015 \\
(0.023)\end{array}$ & & $\begin{array}{l}0.078^{*} \\
(0.042)\end{array}$ & & $\begin{array}{l}-0.015 \\
(0.024)\end{array}$ \\
\hline Log child's savings & & $\begin{array}{c}0.031 \\
(0.019)\end{array}$ & & $\begin{array}{c}0.048 \\
(0.031)\end{array}$ & & $\begin{array}{c}0.027 \\
(0.020)\end{array}$ \\
\hline Parental warmth & & $\begin{array}{c}0.008 \\
(0.043)\end{array}$ & & $\begin{array}{c}0.076 \\
(0.081)\end{array}$ & & $\begin{array}{c}0.013 \\
(0.037)\end{array}$ \\
\hline Reading score & & $\begin{array}{c}0.002 \\
(0.001)\end{array}$ & & $\begin{array}{l}-0.005 \\
(0.003)\end{array}$ & & $\begin{array}{c}0.002 \\
(0.002)\end{array}$ \\
\hline Math score & & $\begin{array}{l}-0.001 \\
(0.002)\end{array}$ & & $\begin{array}{c}0.004 \\
(0.004)\end{array}$ & & $\begin{array}{c}0.000 \\
(0.002)\end{array}$ \\
\hline Observations & 1,152 & 1,152 & 288 & 288 & 1,042 & 1,042 \\
\hline
\end{tabular}

Source: Authors' calculations from PSID and CDS samples.

Notes: 1. Robust standard errors are in parentheses.

2. *** $\mathrm{p}<0.01, * * \mathrm{p}<0.05, * \mathrm{p}<0.1$ 
Table 5. Within-child Estimates of Effects of Verbal Socialization and Role-modeling with Alternative Role-modeling Variables

\begin{tabular}{|c|c|c|c|c|}
\hline \multirow[b]{2}{*}{ Parent talks about giving } & \multicolumn{4}{|c|}{ Dependent Variable: Child's Giving } \\
\hline & $\begin{array}{c}0.128 * * * \\
(0.037)\end{array}$ & $\begin{array}{c}0.130 * * * \\
(0.037)\end{array}$ & $\begin{array}{c}0.130 * * * \\
(0.037)\end{array}$ & $\begin{array}{r}0.129 * * * \\
(0.037)\end{array}$ \\
\hline Parent gives & $\begin{array}{l}-0.004 \\
(0.038)\end{array}$ & & & \\
\hline $\begin{array}{l}\text { Parent gives: alternative } \\
\text { indicator }\end{array}$ & & $\begin{array}{l}-0.057 \\
(0.058)\end{array}$ & & \\
\hline $\begin{array}{l}\text { Parent gives to secular } \\
\text { charities }\end{array}$ & & & $\begin{array}{l}-0.053 \\
(0.037)\end{array}$ & $\begin{array}{c}0.060 \\
(0.106)\end{array}$ \\
\hline $\begin{array}{l}\text { Parent gives to religious } \\
\text { congregations }\end{array}$ & & & $\begin{array}{c}0.024 \\
(0.039)\end{array}$ & $\begin{array}{l}-0.021 \\
(0.134)\end{array}$ \\
\hline $\begin{array}{l}\text { Log amount parent gives to } \\
\text { secular charities }\end{array}$ & & & & $\begin{array}{l}-0.022 \\
(0.019)\end{array}$ \\
\hline $\begin{array}{l}\text { Log amount parent gives to } \\
\text { religious congregations }\end{array}$ & & & & $\begin{array}{c}0.007 \\
(0.022)\end{array}$ \\
\hline Observations & 1,806 & 1,806 & 1,806 & 1,806 \\
\hline
\end{tabular}

Source: Authors' calculations from PSID and CDS samples.

Notes: 1. Robust standard errors clusted at individual level are in parentheses.

2. *** $\mathrm{p}<0.01, * * \mathrm{p}<0.05, * \mathrm{p}<0.1$

3. All regressions include a year dummy. 
Table 6. Within-child Estimates of Effects of Verbal Socialization and Role-modeling for Different Demographic Groups

\begin{tabular}{|c|c|c|c|c|}
\hline & \multicolumn{4}{|c|}{ Dependent Variable: Child's Giving } \\
\hline & $\begin{array}{l}\text { African-Amer. } \\
\text { girls }\end{array}$ & $\begin{array}{l}\text { non-African-Amer. } \\
\text { girls }\end{array}$ & $\begin{array}{c}\text { African-Amer. } \\
\text { boys }\end{array}$ & $\begin{array}{c}\text { non-African-Amer } \\
\text { boys }\end{array}$ \\
\hline \multirow[t]{2}{*}{ Parent talks about giving } & $0.184 * *$ & 0.071 & 0.081 & $0.216^{* * *}$ \\
\hline & $(0.087)$ & $(0.066)$ & $(0.080)$ & $(0.067)$ \\
\hline \multirow[t]{2}{*}{ Role-modeling: parent gives } & -0.135 & $0.143^{*}$ & 0.065 & -0.073 \\
\hline & $(0.087)$ & $(0.074)$ & $(0.071)$ & $(0.069)$ \\
\hline \multirow[t]{2}{*}{ Intact family } & $-0.381 * *$ & -0.106 & 0.213 & -0.168 \\
\hline & $(0.150)$ & $(0.181)$ & $(0.216)$ & $(0.261)$ \\
\hline \multirow[t]{2}{*}{ Female headed } & $-0.211 *$ & 0.107 & 0.117 & -0.185 \\
\hline & $(0.111)$ & $(0.135)$ & $(0.186)$ & $(0.227)$ \\
\hline \multirow[t]{2}{*}{ Family moved } & 0.071 & 0.000 & 0.022 & -0.055 \\
\hline & $(0.065)$ & $(0.061)$ & $(0.076)$ & $(0.062)$ \\
\hline \multirow[t]{2}{*}{ Log family income } & 0.005 & -0.019 & -0.006 & 0.030 \\
\hline & $(0.055)$ & $(0.064)$ & $(0.056)$ & $(0.040)$ \\
\hline \multirow[t]{2}{*}{ Log child's income } & 0.006 & -0.052 & 0.021 & -0.003 \\
\hline & $(0.044)$ & $(0.036)$ & $(0.037)$ & $(0.032)$ \\
\hline \multirow[t]{2}{*}{ Log child's savings } & 0.054 & 0.020 & $-0.042 * *$ & -0.024 \\
\hline & $(0.034)$ & $(0.020)$ & $(0.018)$ & $(0.023)$ \\
\hline \multirow[t]{2}{*}{ Parental warmth } & -0.011 & -0.004 & 0.077 & -0.016 \\
\hline & $(0.064)$ & $(0.051)$ & $(0.053)$ & $(0.067)$ \\
\hline \multirow[t]{2}{*}{ Reading score } & -0.002 & $-0.006^{*}$ & 0.006 & 0.002 \\
\hline & $(0.006)$ & $(0.003)$ & $(0.006)$ & $(0.003)$ \\
\hline \multirow[t]{2}{*}{ Math score } & -0.006 & $0.004 *$ & 0.000 & 0.004 \\
\hline & $(0.004)$ & $(0.002)$ & $(0.003)$ & $(0.003)$ \\
\hline Observations & 376 & 478 & 420 & 532 \\
\hline
\end{tabular}

Source: Authors' calculations from PSID and CDS samples.

Notes: 1. Robust standard errors clusted at individual level are in parentheses.

2. $* * * \mathrm{p}<0.01, * * \mathrm{p}<0.05, * \mathrm{p}<0.1$

3. All regressions include a year dummy. 